\title{
Using life history trade-offs to understand core-transient structuring of a small mammal community
}

\author{
Sarah R. Supp, ${ }^{1,3, \dagger}$ David N. KoOns, ${ }^{2}$ and S. K. Morgan Ernest ${ }^{1,4}$ \\ ${ }^{1}$ Department of Biology and the Ecology Center, Utah State University, Logan, Utah 84322 USA \\ ${ }^{2}$ Department of Wildland Resources and the Ecology Center, Utah State University, Logan, Utah 84322 USA
}

Citation: Supp, S. R., D. N. Koons, and S. K. M. Ernest. 2015. Using life history trade-offs to understand core-transient structuring of a small mammal community. Ecosphere 6(10):187. http://dx.doi.org/10.1890/ES15-00239.1

\begin{abstract}
An emerging conceptual framework suggests that communities are composed of two main groups of species through time: core species that are temporally persistent, and transient species that are temporally intermittent. Core and transient species have been shown to differ in spatiotemporal turnover, diversity patterns, and importantly, survival strategies targeted at local versus regional habitat use. While the core-transient framework has typically been a site-specific designation for species, we suggest that if core and transient species have local versus regional survival strategies across sites, and consistently differ in population-level spatial structure and gene flow, they may also typically exhibit different life-history strategies. Specifically, core species should display relatively low movement rates, low reproductive effort, high ecological specialization and high survival rates compared to transient species, which may display a wider range of traits given that transience may result from source-sink dynamics or from the ability to emigrate readily in a nomadic fashion. We present results from 21 years of capture-mark-recapture data in a diverse rodent community, evaluating the linkages between temporal persistence, local abundance, and trade-offs among life-history traits. Core species at our site conservatively supported our hypotheses, differing in ecological specialization, survival and movement probabilities, and reproductive effort relative to transient species. Transient species exhibited a wider range of characteristics, which likely stems from the multiple processes generating transience in local communities, such as source-sink dynamics at larger regional scales or nomadic life history strategies. We suggest that trait associations among core-transient species may be similar in other systems and warrants further study.
\end{abstract}

Key words: core; dispersal; life-history traits; movement; small mammal; source-sink; temporal persistence; trade-offs; transient.

Received 23 April 2015; accepted 19 May 2015; published 22 October 2015. Corresponding Editor: R. R. Parmenter. Copyright: (C) 2015 Supp et al. This is an open-access article distributed under the terms of the Creative Commons Attribution License, which permits unrestricted use, distribution, and reproduction in any medium, provided the original author and source are credited. http://creativecommons.org/licenses/by/3.0/

${ }^{3}$ Present address: School of Biology and Ecology, University of Maine, Orono, Maine 04469 USA.

${ }^{4}$ Present address: Department of Wildlife Ecology and Conservation, University of Florida, Gainesville, Florida 32611 USA.

† E-mail: sarah@weecology.org

\section{INTRODUCTION}

A pervasive characteristic of ecological communities is that they tend to be composed of a few common species and many rare ones. Traditionally, ecologists have assumed that particular structuring processes are equally impor- tant for explaining patterns of abundance among all species in a community. Alternately, species abundances have been modeled as a product of spatially linked metapopulations or metacommunities (e.g., Hanski 1982, Gaston and Lawton 1989, Gotelli 1991, Urban and Skelly 2006). An emerging view posits that species occurring at a 
site can be sorted into two different groups that should be modeled differently based on temporal patterns of occupancy (Magurran and Henderson 2003): core species that display high temporal persistence (i.e., present most years) and transient species that exhibit low temporal persistence (i.e., present only occasionally). Core species tend to account for most of the abundance or biomass within a particular community. The richness of core species is better predicted by local environmental conditions, presumably reflecting the need for strong local adaptation to outcompete other species and maintain highly abundant, persistent populations in a specific habitat (Ulrich and Ollik 2004, Belmaker 2009, Coyle et al. 2013). In contrast, transient species tend to be rare, and their richness in a local community is better predicted by regional factors (e.g., spatial heterogeneity, regional species pool), presumably because dispersal is a critical process allowing those species to immigrate into particular habitats (Costello and Myers 1996, Milstead et al. 2007, Henderson and Magurran 2014). Because core species at a site require a strong match between their niche requirements and local environmental conditions to maintain populations whereas immigration is the primary process governing the presence of transient species, the core-transient framework suggests that the spatial and temporal scale of processes influencing the two groups should differ.

Although transient species move into a local site from other habitat patches on the landscape, and thus suggests the importance of habitat connectivity and linked populations within a given time frame, the core-transient framework is fundamentally distinct from its spatial analog, the core-satellite framework (Hanski 1982). The core-transient framework assigns species based on temporal persistence at a single site (e.g., the fraction of years where present; Magurran and Henderson 2003, Ulrich and Ollik 2004, Vergnon et al. 2009, Coyle et al. 2013), whereas the coresatellite framework asigns species based on spatial patterns of occurrence across a regional metapopulation (e.g., the fraction of sites in the region where present; Hanski 1982). For example, a species could be identified as regionally "core" because it inhabits a high fraction of habitat patches, but be identified as temporally "transient" at a single site that it inhabits infrequently across a time-series. Here, we use "core" and "transient" to refer to species' occupancy within a time-series of a single site.

Core-transient research has primarily focused on differences between temporally defined groups at a site in how they respond to the same environment. However, if core and transient species differ in the importance of local and regional processes in maintaining populations at a site, they may also differ in the ecological and evolutionary drivers ultimately determining their presence, abundance and diversity (Magurran and Henderson 2003, Dolan et al. 2009, Coyle et al. 2013, Connolly et al. 2014). While little research has focused on this question per se, a rich literature on metapopulations, metacommunities, and the evolution of dispersal suggest that core and transient species could indeed experience different pressures that would select for different ecologies or life history strategies. Core species must successfully compete in, and adapt to, their local biotic and abiotic environment. As such, core species that are strongly governed by local ecological processes experience strong local co-evolutionary pressures with their biotic and abiotic environment (McCauley 2007). Species that are highly adapted to a particular environment can evolve reduced dispersal tendencies in part because of the cost of moving into a maladaptive environment (Kisdi 2002). Limited gene flow through reduced dispersal among populations enhances the role of local natural selection and adaptation for core species (Hanski 1982, McPeek and Holt 1992, Kisdi 2002, Urban et al. 2008). By focusing on using local habitat and reducing the tendency to disperse, core species must also be able to persist through acclimate environmental conditions. This likely involves specialized behaviors or traits to allow persistence under poor conditions (Hanski 1982, Clutton-Brock 1991, Ghalambor and Martin 2000, Kisdi 2002).

The ecological and evolutionary pressures on transient species are more complicated. Although there is only one way to be core, there are two primary processes that may generate transient species within a local community, each with different resulting expectations of the eco-evolutionary pressures imposed. One process that can generate transients in a local community is source-sink dynamics (e.g., Hanski 1982). 
Source-sink transients are species that are core at other sites on the landscape through time, but not in the focal site. Because they are welladapted elsewhere and immigration from the adapted source population should swamp local adaption to the new environment (Holt and Gaines 1992, Kawecki and Holt 2002, Lenormand 2002, Kawecki 2008), we would expect sourcesink transients to retain many of the same general life history characteristics as core species, except with low temporal occupancy.

In contrast to source-sink transients, some transients may form short-term reproducing populations before disappearing and potentially reappearing later via immigration. Processes that could generate this type of transient include opportunistic tracking of shifting resources across a region (e.g., Wiens 2001, Roshier and Reid 2003, Milstead et al. 2007, Jonzen et al. 2011) or competition-colonization tradeoffs (e.g., Diamond 1974, Kneitel and Chase 2004). Both cases create what we will call nomadic transientsindividuals that form reproducing populations for short periods of time in a local habitat before moving elsewhere on the landscape. Nomadism results from irregular, non-sedentary behavior, and differs from migration in that movements may be made at any time of year following any path (e.g., no fixed breeding grounds, low home range stability), and may occupy a large portion of the animal's life (Baker 1978, Roshier and Reid 2003). Nomadic transients are strongly governed by regional ecological processes with high levels of movement across the landscape that reflects demographic processes or spatial rearrangement in response to changing conditions though time (O’Donnell 2001, Roshier and Reid 2003).

Increased individual movement may impact the long-term evolutionary dynamics of nomadic transient species if: (1) high gene flow homogenizes gene pools and inhibits local adaptation (Urban et al. 2008) or (2) intermediate gene flow increases the capacity for local adaptation in unstable habitats via novel subsidies from the regional gene pool (Roshier and Reid 2003, Urban and Skelly 2006, Loeuille and Leibold 2008). Both the high gene flow and intermediate gene flow scenarios suggest that on average transient species should be less adapted to local biotic and abiotic conditions than core species. Because they are less well adapted to local conditions, they are expected to be at a competitive disadvantage, except for their ability to exploit novel conditions in unstable environments. If nomadic transient species depend on a regional life history strategy that requires the ability to track suitable environmental conditions and use heterogeneous landscapes, then they should be strongly associated with traits that enable them to traverse non-ideal habitat patches and to colonize new suitable habitat patches as they arise (McCauley 2007). Increased dispersal ability and movement rates come with costs that may include increased mortality risk and increased time and energetic expenditure (Murray 1967, Hanski 1982, Waser 1985, Rousset and Gandon 2002). To maximize fitness amidst such costs, it may be optimal for nomadic transient species to trade-off survival investment toward increased reproductive allocation (e.g., CluttonBrock 1991, Stearns 1992) and they may have thus evolved associations with life-history traits such as low survival probability, high fecundity, early age of primiparity, and resource or habitat generalism (Diamond 1974, Charlesworth 1980).

The core-transient framework can thus provide a key connection of the slow-fast theory of life history evolution (Ricklefs and Wikelski 2002, Sibly and Brown 2007) with movement and habitat use strategies. From theoretical and empirical studies on dispersal, metapopulations, and metacommunities, we might expect a life history strategy for core species focused on localscale coexistence to include low movement rates, low mortality rates, high immune function, limited gene flow among populations, high specialization for local conditions, and decreased fecundity. Source-sink transients should show similar trait correlations as core species, except that they should exhibit lower abundances and temporal persistence and have little genetic differentiation between source and sink populations (Gaggiotti 1996). For nomadic transients, we expect the opposite set of characteristics from core species. Nomadic species at a site should generally be expected to have higher movement rates, be able to reproduce in a wider range of habitats, exhibit increased fecundity, higher gene flow among populations, but lower survival (Mueller and Fagan 2008, Baguette et al. 2013). While this possible link between the coretransient framework and life-history traits is 
intriguing, there has been no empirical evaluation, especially examining correlations in traits across species within the same community.

We use 21-years of data from a diverse desert rodent community containing information on movement, mark-recapture rates, and reproduction to test aspects of the hypothesis that core species have fundamentally different life-history strategies than transient species as expected from differences in local vs. regional habitat use. We predict that core species will generally be associated with relatively low movement rates, high survival rates, and low fecundity. We predict that transient species will display a mixture of traits, depending on whether they are source-sink or nomadic transients, but generally have more incidence of high movement rates, low survival rates, high fecundity, and resource or habitat generalism (Fig. 1).

\section{Materials and Methods}

\section{Study site and data}

We evaluated the relationship between life history traits and core-transient status at our site using 21 years (1989-2009) of capture-markrecapture (CMR) data for rodents from a longterm experimental site in the Chihuahuan desert in southeastern Arizona (the Portal Project field site; Ernest et al. 2009). The study site consists of 24, 0.25 ha fenced plots $(50 \times 50 \mathrm{~m})$. Each month, year-round, plots are trapped on a grid consisting of 49 evenly spaced permanent stakes to survey the rodent community and to maintain experimental treatments. Four gates cut into each side of the fenced plots allow free passage of rodents in and out of plots. Large-bodied and behaviorally dominant kangaroo rats (Dipodomys spp.) have enlarged auditory bullae that make it possible to selectively exclude them from plots that have a smaller gate size $(n=8)$. Total rodent removal plots have no gates $(n=6)$, while control plots $(n=10)$ have relatively large gates that allow all species access (Brown 1998). Rodents are known to follow barriers until a path opens (Singleton et al. 1998), ensuring that plot gates are discovered, and there are not significant differences in species colonization of the plots compared to the natural landscape (Brown and Munger 1985). Upon capture, each individual was marked by toe clipping, ear tags or with a permanent, subcutaneous passive integrated transponder (PIT) tag that allowed it to be uniquely identified upon capture. For each captured individual, we recorded species, sex, reproductive status, hind foot length, weight, and individual PIT tag. For our analysis, we right-censored data from individuals after the point that they were captured on total rodent removal plots, or from kangaroo rat individuals captured on kangaroo rat removal plots because these individuals were subsequently removed from the study site.

Since the small mammal community includes diverse species $(n=21)$ representing a suite of different feeding guilds and life history strategies (Table 1), our site is ideal for evaluating certain traits associated with core and transient species in 3 main feeding guilds: granivores $(n=15)$, folivores $(n=4)$ and carnivores $(n=2)$. At our site, species across the three guilds have a wide range of body sizes (4-280 g) and divergent evolutionary histories (Bininda-Emonds et al. 2007), leading to differing levels of adaptation to the arid environment, which results in them being differently suited to local and regional habitat use. During 1989-1999, individuals were marked using ear and toe tags, and during 20002009, individuals were mainly marked with PIT tags. We conducted extensive data cleaning and error checking to ensure that potential problems in the data (e.g., duplicate tags, uncertainty in sex or species) were resolved. In cases where the data with identical tags could be clearly partitioned into unique individuals, we assigned new unique tag numbers to each individual. In cases where data could not be clearly partitioned into individuals, or where species identity was questionable, the data were excluded from analysis.

Core and transient species status was assigned based on temporal persistence, as defined by the proportion of years that each species was present (1989-2009) on control plots at our site. Species that were present in at least $2 / 3$ of the years $(\geq 0.66)$ were considered core (sensu Coyle et al. 2013). Species that were present less than $1 / 3$ of the years $(\leq 0.33)$ were considered transient. All other species were considered intermediate temporal status. 


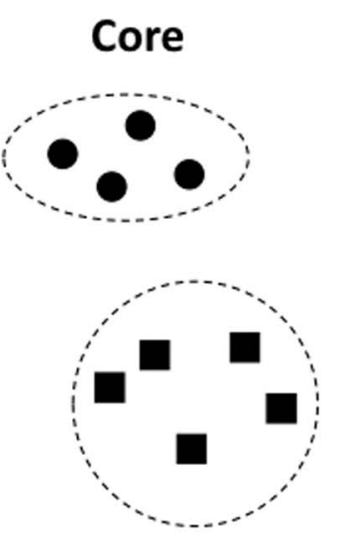

Present in focal community in the majority of years $(>66 \%)$

\section{Source-sink Transient}
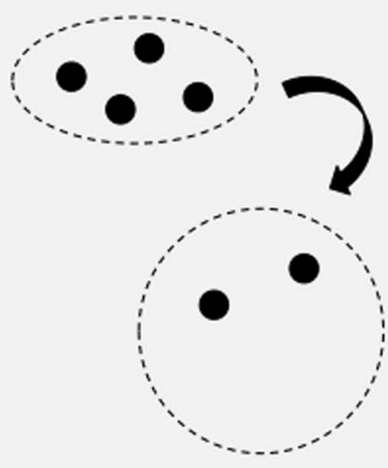

Present in focal community intermittently ( $<33 \%$ years). Emigrate from nearby source community.

\section{Nomadic Transient}

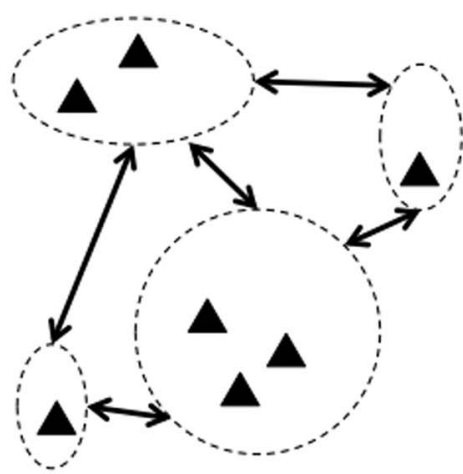

Present in focal community intermittently ( $<33 \%$ years). Nomadic movements track niche, and they are perpetual colonizers.

\begin{tabular}{|c|c|c|}
\hline $\begin{array}{l}\text { Highly adapted to habitat/ } \\
\text { resources in focal community }\end{array}$ & $\begin{array}{l}\text { Adapted to habitat/resources in } \\
\text { source community, but not } \\
\text { necessarily to focal community }\end{array}$ & $\begin{array}{l}\text { Habitat/resource generalist that } \\
\text { opportunistically colonizes in response } \\
\text { to available niches }\end{array}$ \\
\hline $\begin{array}{l}\text { Generally } \\
\text { dominant } \\
\text { and } \\
\text { abundant } \\
\text { in focal } \\
\text { community }\end{array}$ & $\begin{array}{l}\text { May become } \\
\text { abundant for } \\
\text { short time } \\
\text { periods, but } \\
\text { are generally } \\
\text { rare }\end{array}$ & $\begin{array}{l}\text { May become } \\
\text { abundant for } \\
\text { short time } \\
\text { periods, but } \\
\text { are generally } \\
\text { rare }\end{array}$ \\
\hline Competitively dominant & Competitively inferior & Competitively inferior \\
\hline $\begin{array}{l}\text { Self investment strategy } \\
\text { High survival } \\
\text { Low fecundity }\end{array}$ & $\begin{array}{l}\text { High survival in source community } \\
\text { Lower survival in focal community } \\
\text { Lower fecundity in focal community }\end{array}$ & $\begin{array}{l}\text { Offspring investment strategy } \\
\text { Low survival } \\
\text { High fecundity }\end{array}$ \\
\hline Strong fidelity to "home" & $\begin{array}{l}\text { Colonize population sinks in } \\
\text { response to density dependent } \\
\text { dynamics in source community }\end{array}$ & Strong colonizers \\
\hline $\begin{array}{l}\text { Movements tied strongly to } \\
\text { defending home resources/ } \\
\text { territory. Reduced movement. }\end{array}$ & $\begin{array}{l}\text { Movements tied strongly to } \\
\text { obtaining and defending home } \\
\text { territory. Reduced movement. }\end{array}$ & $\begin{array}{l}\text { Movements tied to obtaining resources } \\
\text { and exploring available territory/niches. } \\
\text { Increased movement tendencies. }\end{array}$ \\
\hline $\begin{array}{l}\text { Relatively low gene flow among } \\
\text { populations }\end{array}$ & $\begin{array}{l}\text { Relatively low gene flow among } \\
\text { populations }\end{array}$ & $\begin{array}{l}\text { Intermediate to high gene flow among } \\
\text { populations }\end{array}$ \\
\hline $\begin{array}{l}\text { Circular habitat is "focal" } \\
\text { open. Core-transient des } \\
\text { hypothesize that tempor }\end{array}$ & ommunity. Dashed lines repr & $\begin{array}{l}\text { ent that communities are } \\
\text { in a focal community, but we } \\
\text { traits. }\end{array}$ \\
\hline
\end{tabular}

Fig. 1. Hypothesized relationships between core-transient status and life history trade-offs. Temporal persistence is predicted to be correlated with life-history traits including survival, reproduction, movement patterns, and resource use. 
Table 1. Summary of species traits from the field data. Species-level trait details summarizing feeding guild, coretransient status, total number of individuals tracked through the study $(N)$, mean body mass across all recorded weights, mean yearly reproductive effort, and species-level benchmarks defining where each movement distribution transitions into long-distance movements. Yearly reproductive effort was estimated by taking weighted average of the number of individual females marked as reproductive 0-4 times per year. An ellipsis indicates that we could not generate multistate CMR estimates due to small sample size $(N \leq 10)$.

\begin{tabular}{|c|c|c|c|c|c|c|c|c|c|}
\hline Species & Guild & Status & $N$ & $\begin{array}{l}\text { Mean } \\
\text { mass } \\
(g)\end{array}$ & $\begin{array}{l}\text { Mean no. } \\
\text { reproduction } \\
\text { events/year }\end{array}$ & $\begin{array}{l}\text { Movement } \\
\text { benchmark } \\
(\mathrm{m})\end{array}$ & $\Phi(\mathrm{SE})$ & $p$ (SE) & $\Psi(\mathrm{SE})$ \\
\hline Dipodomys merriami & Gran. & Core & 1972 & 43.64 & 0.52 & 33.13 & $0.80(0.00)$ & $0.60(0.01)$ & $0.06(0.00)$ \\
\hline D. ordii & Gran. & Core & 1030 & 48.32 & 0.47 & 30.35 & $0.75(0.01)$ & $0.63(0.01)$ & $0.03(0.00)$ \\
\hline D. spectabilis & Gran. & Intermed. & 41 & 115.01 & 0.21 & 24.70 & $0.83(0.02)$ & $0.66(0.04)$ & $0.02(0.01)$ \\
\hline Chaetodipus baileyi & Gran. & Core & 2063 & 31.77 & 0.40 & 29.96 & $0.84(0.00)$ & $0.56(0.01)$ & $0.04(0.00)$ \\
\hline C. penicillatus & Gran. & Core & 2818 & 17.01 & 0.40 & 44.33 & $0.83(0.00)$ & $0.21(0.00)$ & $0.06(0.02)$ \\
\hline C. hispidus & Gran. & Transient & 10 & 31.74 & 0.43 & 16.49 & & & \\
\hline C. intermedius & Gran. & Transient & 20 & 18.46 & 0.14 & 33.96 & $0.79(0.05)$ & $0.25(0.07)$ & $0.06(0.04)$ \\
\hline Perognathus flavus & Gran. & Core & 648 & 8.12 & 0.54 & 41.50 & $0.78(0.01)$ & $0.23(0.01)$ & $0.06(0.01)$ \\
\hline Peromyscus eremicus & Gran. & Core & 479 & 21.47 & 0.53 & 107.18 & $0.63(0.02)$ & $0.32(0.02)$ & $0.37(0.04)$ \\
\hline Pe. maniculatus & Gran. & Intermed. & 398 & 21.41 & 0.46 & 120.13 & $0.62(0.02)$ & $0.28(0.03)$ & $0.53(0.05)$ \\
\hline Pe. leucopus & Gran. & Transient & 77 & 22.41 & 0.24 & 56.05 & $0.46(0.06)$ & $0.44(0.11)$ & $0.12(0.06)$ \\
\hline Reithrodontomys megalotis & Gran. & Core & 1180 & 10.71 & 0.23 & 95.17 & $0.63(0.01)$ & $0.27(0.01)$ & $0.33(0.20)$ \\
\hline R. montanus & Gran. & Transient & 18 & 9.01 & 0.67 & 365.01 & $0.72(0.14)$ & $0.07(0.06)$ & $0.86(0.15)$ \\
\hline R. fulvescens & Gran. & Transient & 11 & 13.90 & 1.50 & 63.42 & $0.81(0.05)$ & $0.63(0.08)$ & $0.22(0.08)$ \\
\hline Baiomys taylori & Gran. & Transient & 106 & 8.76 & 0.26 & 70.65 & $0.63(0.05)$ & $0.22(0.05)$ & $0.12(0.05)$ \\
\hline Sigmodon hispidus & Foliv. & Intermed. & 268 & 88.84 & 0.12 & 39.56 & $0.45(0.04)$ & $0.38(0.06)$ & $0.08(0.03)$ \\
\hline S. fulviventer & Foliv. & Intermed. & 151 & 66.01 & 0.07 & 67.06 & $0.66(0.03)$ & $0.35(0.04)$ & $0.14(0.03)$ \\
\hline S. ochrognathus & Foliv. & Transient & 27 & 55.55 & 0.37 & 91.85 & $0.70(0.07)$ & $0.21(0.07)$ & $0.31(0.14)$ \\
\hline Neotoma albigula & Foliv. & Core & 255 & 167.05 & 0.66 & 39.76 & $0.79(0.01)$ & $0.33(0.02)$ & $0.10(0.02)$ \\
\hline Onychomys torridus & Carn. & Core & 952 & 23.81 & 0.49 & 80.87 & $0.76(0.01)$ & $0.42(0.01)$ & $0.09(0.01)$ \\
\hline O. leucogaster & Carn. & Core & 127 & 30.16 & 0.54 & 152.45 & $0.77(0.02)$ & $0.37(0.03)$ & $0.27(0.04)$ \\
\hline
\end{tabular}

\section{Movement, survival, and fecundity}

Using individual-level recapture data, we assessed movement characteristics for each species. Here, we define individual movement at each time-step relative to the individual's previous capture location, and not in a geographic context defined by the individual's birthplace, burrow, or location relative to other individuals. We were unable to measure geographic dispersal (e.g., relative to natal location) using our dataset, but we assume that patterns of individual movement (including maintenance, breeding, foraging, and exploratory movements) are correlated with and encompassed by dispersal, which is an outcome of movement (Roshier and Reid 2003). Locations of the permanently marked trap stakes were recorded in 2010 using ProMark3 GPS Units with error $<2 \mathrm{~cm}$. We recorded the distance in meters between trap stakes among chronologically ordered capture histories for each individual. For each species, we binned the individual movement data by 6 -meter increments that roughly represent the distance between stakes (with bin 1 representing distance 0 -
3 meters, or recapture at the same stake), and plotted the data in histograms. For each species, we calculated the modal distance and the mean plus one standard deviation of the $\log (Y+1)$ transformed data to determine a species-level benchmark at which each movement distribution transitions into long-distance movements. We chose this transformation to meet the assumptions of normality and because there are many 0 m movements (Sokal and Rohlf 2012). For each species, these histograms provide insight into the frequency at which individuals move short versus long distances. Using the combined individual movement distances of the core species within each feeding guild (granivore, folivore, and carnivore), we set the mean plus one standard deviation of $\log (\mathrm{Y}+1)$-transformed data as our guild-level benchmark defining a short versus a long distance movement to compare across all species. We used this method because home range size likely differs based on trophic group (Mace and Harvey 1983).

To more thoroughly evaluate life-history relationships between movement and apparent 
survival, conditional on recapture probability, we used a multistate capture-mark-recapture (CMR) modeling approach in Program Mark version 7.0 (White and Burnham 1999, White and Cooch 2012) through the $R$ programming environment 3.0.2 ( $\mathrm{R}$ Core Development Team 2013) and package RMark (Laake and Rexstad 2008, Laake 2013). To address our questions of whether core and transient species differ in apparent survival $(\Phi)$, recapture $(p)$, and movement probabilities $(\psi)$, we used a two-state model where all species were first recorded in state 1 , and were switched to state 2 (or from state 2 back to state 1 ) conditional on the distance between trapping stakes upon recapture being greater than the guild-level benchmark defining short distance movements. In this two-state CMR model, transitioning between states indicates long distance movement, and staying in the same state indicates short distance movement, conditional on apparent survival and recapture probabilities. We defined apparent survival probability as the probability that an individual alive in trapping period $i$ survived and did not emigrate from the entire study area by trapping period $i+1$. We defined recapture probability at trapping period $i$ +1 as the probability that a live individual anywhere on the study area was recaptured in a trap. All probabilities were measured over a time scale of approximately one month, the time between trapping events. To address inconsistencies in the data, we controlled for omitted trap periods (when trapping did not occur or the site was only partially trapped) by fixing recapture probability to zero for those occasions. It should be noted that we could not differentiate between permanent emigration and death, which may affect interpretation of our survival estimates. Thus, low apparent survival probabilities may indicate low actual survival, high permanent emigration from the entire study area, or both. We evaluated each species separately in RMark to estimate apparent survival, recapture, and transition probabilities (White and Cooch 2012), except for transient granivores, which we grouped together because there were not enough captures to analyze species separately. Pooling data for all species into a single dataset, and designating species or strategies with factors, led to an extremely large CMR dataset that prohibited computational analysis using MARK and
RMark. We thus used post hoc analyses to compare the estimates for core versus intermediate and transient species. For further details on our RMark analysis, please refer to our code, which is maintained online in a public GitHub repository along with the data (https:/github. com/weecology/portal-rodent-dispersal) and is available in the online supplement.

To assess reproductive effort for each species, we tracked the reproductive history for captured individual females within each calendar year. We considered females with enlarged and/or red nipples or who were pregnant (researcher could feel embryos) to be actively reproducing. If a female was marked in reproductive condition during consecutive trapping periods, we assumed it to be a single reproductive event. Reproductive condition recorded across nonconsecutive trapping periods was considered as multiple reproductive events. We used data from females because males display reproductive signals for a larger portion of the year, and male reproductive status does not necessarily indicate recent copulation or reproductive success. For each species, we also recorded litter size and number of litters per year from the literature (Hoffmeister 1986).

To compare the life-history traits among groups, we standardized the data and results to account for different units $([(x-\operatorname{mean}(x)) / \operatorname{sd}(x)])$ and controlled for the influence of phylogenetic relatedness on our results (Felsenstein 1985). We used a generalized least squares model to test for the correlation of traits and trait trade-offs with phylogenetic relatedness (APE, Paradis et al. 2004; Geiger, Harmon et al. 2008; picante, Kembel et al. 2010) based on a published mammalian phylogeny (Bininda-Emonds et al. 2007; PhyloOrchard, O'Meara et al. 2013) and using the assumption of linear decrease in trait covariance (bm gls; Brownian motion model). We also compared species using a linear regression and PCA biplots to determine the relative influences of temporal status, feeding guild, and phylogenetic relatedness on movement patterns and life history traits.

\section{RESULTS}

\section{Core-transient species designation}

During the 21-year study period, we captured 
SUPP ET AL.

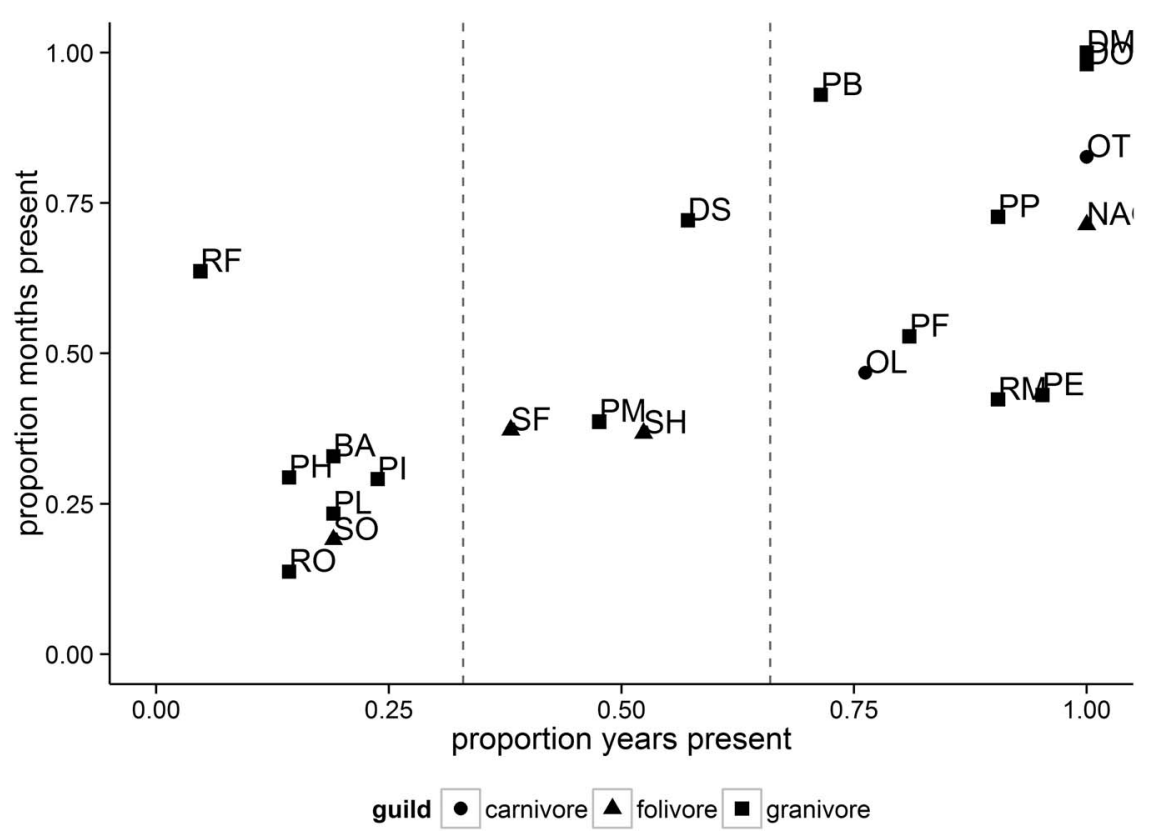

Fig. 2. The proportion of years and the mean proportion of months that a species was present in the study period (1989-2009). We designated core $(\geq 0.66)$, intermediate $(<0.66$ and $>0.33)$ and transient $(\leq 0.33)$ status based on the proportion of years only. Two-letter abbreviations refer to the species names (B. taylori, BA; C. baileyi, PB; C. hispidus, PH; C. intermedius, PI; C. penicillatus, PP; D. merriami, DM; D. ordii, DO; D. spectabilis, DS; N. albigula, NA; O. leucogaster, OL; O. torridus, OT; P. flavus, PF; Pe. eremicus, PE; Pe. leucopus, PL; Pe. maniculatus, PM; R. flavescens, RF; R. megalotis, RM; R. montanus, RO; S. fulviventer, SF; S. hispidus, SH; S. ochrognathus, SO).

12,651 individuals from the 21 species included in the analysis (Table 1). Based on the proportion of years that each species was present, we placed species into three temporal persistence categories (Fig. 2) consisting of 10 core (Dipodomys ordii, D. merriami, Chaetodipus baileyi, C. penicillatus, Perognathus flavus, Peromyscus eremicus, Reithrodontomys megalotis, Neotoma albigula, Onychomys torridus, and O. leucogaster), 7 transient species (C. hispidus, C. intermedius, Peromyscus leucopus, R. montanus, R. fulvescens, Baiomys taylori, and Sigmodon ochrognathus), and 4 intermediate species (D. spectabilis, Peromyscus maniculatus, S. fulviventer, and S. hispidus). Granivores and folivores were represented across all three persistence categories, but both carnivorous species were designated "core" (Table 1). We removed Chaetodipus hispidus from our main comparisons because there were only 10 individuals with recaptures and we could not run multistate CMR models on such a small sample. Since transient species were rarely captured at the site and thus do not have enough data points for robust statistical analysis, we focus our results on the comparison between core and non-core species, where non-core refers to intermediate and transient species grouped together, generally.

\section{Movement, survival, and fecundity}

For all the species, movement distances between recaptures were strongly unimodal and left-skewed. Transient and intermediate species generally had a longer tail on their movement distributions than core species and distributions for many non-core species had a secondary mode, suggesting more long-distance movements, larger home ranges, and possible emigration off-site (Table 1, Fig. 3; Appendix: Fig. A1). Transient species that had few long-distance movements may be attributed to high mortality, low detectability on the site, low recapture due to rapid movement off the site, or a combination of these. Core species tended to move shorter distances (median species-level movement benchmark; core $=42.91 \mathrm{~m}$ [29.96-152.45]; non- 

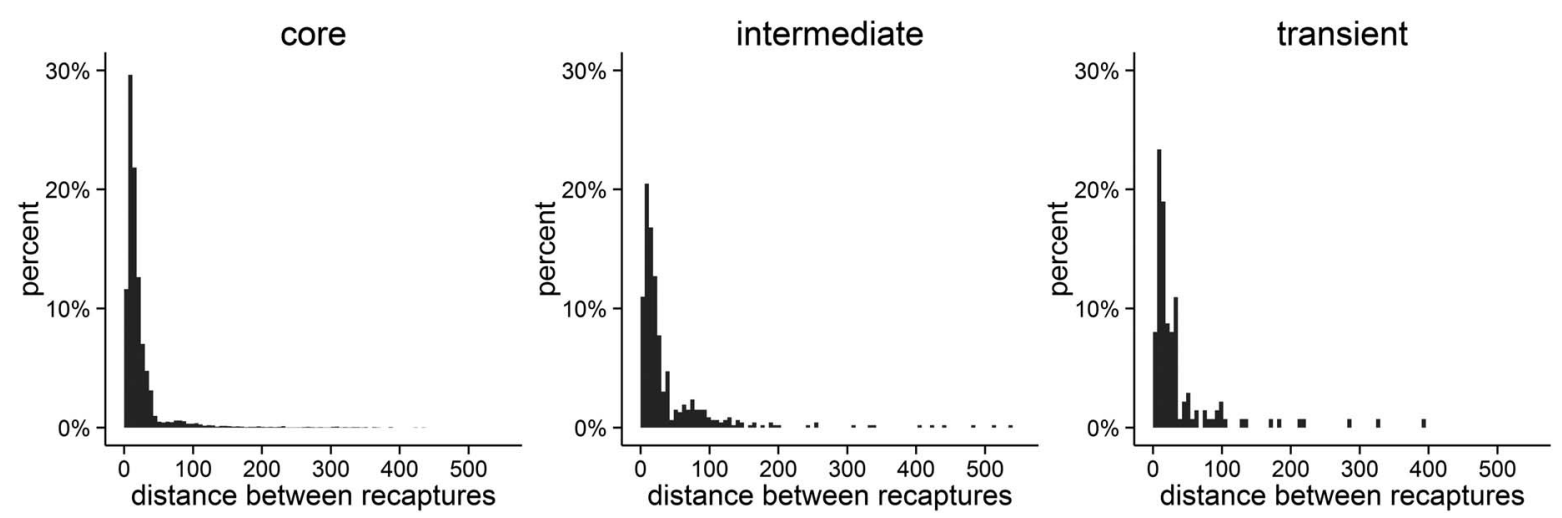

Fig. 3. Histograms grouped by temporal persistence for the distances at which individuals were recaptured each month. Note that the y-axes are the percent of observations for each bin, but that there is a large difference in total number of individuals captured in each group, that is not represented in the histograms (but see Table 1).

core $=65.24$ [24.70-365.01]. Among granivores, core species had a lower frequency of moving a relatively far distance away from the previous trap location (median benchmark $=41.50 \mathrm{~m}$ ) than intermediate (median benchmark $=72.42 \mathrm{~m}$ ) or transient granivore species (median benchmark = $63.42 \mathrm{~m}$; Table 1). Among folivores, the core species $N$. albigula generally moved shorter distances (benchmark $=39.76 \mathrm{~m}$ ) than the intermediate (benchmark $=53.31 \mathrm{~m}$ ) and transient species (mean benchmark $=91.85 \mathrm{~m}$; Table 1). Core guild-level movement benchmarks were used to parameterize the CMR model and differed across trophic groups (granivore, benchmark $=36.70$; folivore, benchmark $=39.76$; carnivore, benchmark $=88.07$ ).

When using the two-state CMR model in Mark to compare apparent survival, recapture, and movement probabilities among core and transient species, differences were most pronounced among core granivores versus transient and intermediate granivores (Table 1). On average, core species had a lower probability of moving a long distance (mean $\psi_{\text {core }}=0.14$ [range 0.03$0.37])$, but higher recapture $\left(p_{\text {core }}=0.39\right.$ [range 0.21-0.63]) and apparent survival probabilities (mean $\Phi_{\text {core }}=0.76$ [range $\left.0.63-0.84\right]$ ) than noncore species (mean $\psi_{\text {non-core }}=0.25$ [range 0.020.86], mean $p_{\text {non-core }}=0.35$ [range 0.07-0.66], mean $\Phi_{\text {non-core }}=0.67$ [range $\left.0.45-0.83\right]$ ).

Reproductive results from the field data were best explained by phylogeny. For all species in Heteromyidae (5 core and 3 non-core), the majority of captured females were never recorded in reproductive condition (Table 1; Appendix: Fig. A2). However, despite generally much lower abundance, species in Cricetidae were observed in reproductive condition more often. For example, nearly $50 \%$ of Peromyscus eremicus (core) and $P$. maniculatus (non-core) were recorded in reproductive condition at least once per year (Table 1) and N. albigula (core) females were often found in reproductive condition. However, Sigmodon (non-core) females were almost never recorded as reproductive (Table 1). The lack of observed reproduction may suggest that Sigmodon rarely reproduce at the site or that sampling error associated with the small number of captures affected our results. Onychomys (core) females were rarely captured when reproductive, but other data suggest that $O$. torridus may reproduce multiple times per year (Tables 1 and 2).

\section{Phylogeny and trade-offs}

PCA results suggested that species can be grouped in multivariate space by their traits and core-transient status (Fig. 4), and that traits appear to be strongly conserved within family (Appendix: Fig. A3). Phylogeny (family) was a significant predictor of $\psi$ (linear model; $\operatorname{lm}(\psi \sim$ family $\left.), p=0.016, r^{2}=0.28\right), \Phi(\operatorname{lm}(\Phi \sim$ family $), p$ $\left.=0.006, r^{2}=0.35\right)$, and mean abundance ( $\mathrm{lm}$ (abundance $\sim$ family), $p=0.004, r^{2}=0.37$ ), but not for the proportion of years a species was present. Mean abundance was positively related to the proportion of years a species was present in the study area when phylogeny was controlled for (bm gls, $p=0.005)$. Body size was not a 
Table 2. Summary of reproductive life-history traits. An ellipsis indicates no data from either reference.

\begin{tabular}{|c|c|c|c|c|c|}
\hline Species & Status & Litter size & Mean litter size & No. litters/year & Typical breeding months \\
\hline Dipodomys ordii $\dagger$ & Core & $2-3$ & 2.37 & $1-2$ & February-July \\
\hline D. merriami† & Core & $2-3$ & 2 & $1-2$ & March-October \\
\hline Chaetodipus baileyi† & Core & $1-6$ & 3.6 & $\ldots$ & April-August \\
\hline C. penicillatus $\dagger$ & Core & $2-8$ & 4.72 & 1 & April-August \\
\hline Perognathus flavusं & Core & $1-6$ & 4 & 1 & April-August \\
\hline Peromyscus eremicus $\dagger$ & Core & $1-4$ & 2.53 & $1-4 \dagger$ & Year-round \\
\hline Reithrodontomys megalotis $\dagger$ & Core & $3-7 \ddagger$ & 3.6 & $1-10$ & Year-round \\
\hline Neotoma albigula & Core & $1-4$ & 1.95 & $\geq 1$ & Year-round \\
\hline Onychomys torridus & Core & $2-5$ & 3.45 & $\ldots$ & March-October \\
\hline O. leucogaster & Core & $3-5$ & 4 & & March-September \\
\hline D. spectabilis $\dagger$ & Intermediate & $1-3$ & 2.1 & $1-2$ & January-August \\
\hline P. maniculatus & Intermediate & $1-6$ & 4.29 & $2-4 \dagger$ & Year-round \\
\hline Sigmodon hispidus & Intermediate & $2-10$ & 5.6 & $1-9$ & Year-round \\
\hline S. fulviventer & Intermediate & $4-6 \ddagger$ & $\ldots$ & & Year-round \\
\hline C. hispidusं & Transient & $4-7 \ddagger$ & & $1-2 \ddagger$ & \\
\hline C. intermedius $\dagger$ & Transient & $1-7$ & 3.94 & & March-July \\
\hline P. leucopus $\dagger$ & Transient & $2-5$ & 3.61 & $>1 \ddagger$ & February-October \\
\hline R. montanus $\dagger$ & Transient & $1-9 \$$ & $4 \$$ & $\ldots$ & Year-round $\$$ \\
\hline R. fulvescens $\dagger$ & Transient & $2-4$ & & & Year-round \\
\hline Baiomys taylori $\dagger$ & Transient & $1-5 \ddagger$ & 2.49 & $1-9$ & Year-round \\
\hline S. ochrognathus & Transient & $2-6$ & $\ldots$ & $\ldots$ & Year-round \\
\hline
\end{tabular}

$\uparrow$ Species directly competing for resources in the granivore feeding guild.

\$ Data from Hoffmeister (1986), with missing data filled from Wilson and Ruff (1999).

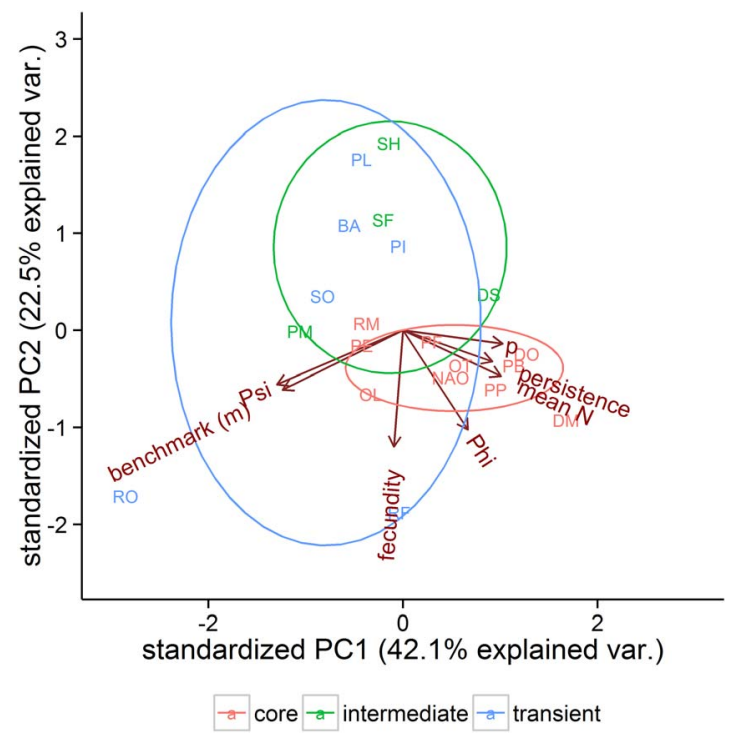

Fig. 4. PCA biplot with confidence ellipses for temporal persistence. The relationship of movement (Psi and benchmark), mean number of observed reproductive events for individuals of each species per year (fecundity), apparent survival (Phi), recapture rates (p), mean abundance, and the proportion of years a species was present (persistence). Two letter abbreviations refer to species names as presented in Fig. 2. PCA axes 1 and 2 explained a total $64.6 \%$ of the variation. significant predictor for the proportion of years present, mean abundance, survival, reproduction, or movement (bm gls, $p>>0.05$ ). We did not detect strong movement-survival trade-offs or movement-reproduction trade-offs in this community using linear regression or phylogenetic methods (Appendix: Figs. A4 and A5). There was a relationship between observed modal movement distance and temporal persistence $(\operatorname{lm}$ (distance mode $\sim$ proportion years present), $p=0.03, r^{2}=0.23$; bm gls, $p=0.05$ ) where species that persisted longer moved shorter distances.

\section{Discussion}

Our study provides the first test, to our knowledge, of whether life-history traits are associated with the temporal persistence patterns of species in a community. Life-history traits were generally conserved within evolutionary lineages, which in our system are also related to higher or lower degrees of adaptation to desert environments. Our results provide some indication that life history traits are also linked to the core-transient structure among species at our site. Analysis of the movement, survival and reproduction data indicated that core species at our site moved relatively short distances and had higher apparent survival rates than intermediate 
and transient species, consistent with our predictions. Core species were generally more abundant than transient or intermediate species, which may suggest greater competitive dominance or ecological specialization. Transient species at our site exhibited lower apparent survival and moved longer distances, on average, than core species, but the range of estimates within this group varied widely. We interpret the high variation in survival and movement estimates across species within the intermediate and transient groups as support for the idea that this heterogeneous group includes both source-sink and nomadic transients. Among traits, we did not detect strong movement-survival trade-offs, and too few reproductive events were observed to test for survival-reproduction trade-offs.

Other research at our site also supports the idea that our core and transient species have different effects on community structure and resource use. Core species that exhibit high selfinvestment, strong competitive ability, and strong local adaptation are also expected to successfully exploit most of the available resources at a local site (Kneitel and Chase 2004). The most abundant core species at our site are indeed responsible for the majority of resource consumption (Thibault et al. 2004), are behaviorally dominant (Dipodomys spp.; Reichmann and Price 1993), and have cascading impacts on rodent and plant communities (Brown and Heske 1990, Heske et al. 1994, Valone and Schutzenhofer 2007). Pocket mice (Chaetodipus spp.), another group of core species, become dominant in the absence of kangaroo rats (Ernest and Brown 2001). Therefore, it is generally true in this system that species with lower movement, higher survivorship, and potentially lower reproductive rates are also the competitively dominant species responsible for the majority of resource consumption (Thibault et al. 2004).

The life-history estimates for transient and intermediate species $(n=11)$ generally supported our hypotheses. We expected that results for this group of species would exhibit broad interspecific variation because of the presence of both nomadic and source-sink transients. Unfortunately, it is not possible to definitively distinguish between these groups using our data, but using a combination of our results and the well-studied natural history of these species, we can make some informed predictions. Species that exhibited trait correlations more similar to core species could be source-sink transients (Lenormand 2002, Kawecki 2008), or could be undergoing local extinction (Gibson et al. 1999). Because they are core somewhere else, source-sink transients may generally be inferior competitors that temporarily colonize in response to resource pulses and density dependent dispersal at other locations, both of which could create a sourcesink dynamic over time (Heske et al. 1994, Thibault et al. 2004, Milstead et al. 2007). Dipodomys and Chaetodipus species that were not core at our site are either undergoing local extinction due to directional habitat change $(D$. spectabilis; Valone et al. 2002, Thibault et al. 2004) or are not adapted to the habitat at our site (C. intermedius and C. hispidus; Hoffmeister 1986, Paulson 1988, Williams et al. 1993) and their occasional presence can likely be attributed to temporary dispersal from nearby source populations (Wilson and Ruff 1999). At our site, Sigmodon and Reithrodontomys are prairie-adapted species (Webster and Jones 1982, Hoffmeister 1986) that usually arrive during years and seasons where climatic conditions lead to higher than normal grass cover (Thibault et al. 2004). During our study period these species had relatively low abundance and were rarely recorded in reproductive condition-strong evidence that our site represents a habitat sink for these populations. Species that exhibited trait correlations different from core species could be nomadic transients. Peromyscus maniculatus and leucopus at our site were generally rare, moved longer distances more often, potentially reproduce multiple times per year, and use a wider resource base than the core species (Hoffmeister 1986, Wilson and Ruff 1999), evidence that these species could readily colonize new locations. In addition, Baiomys taylori seem to be dependent on high ground cover, and thus requiring populations to nomadically track habitats receiving more than the usual amount of water (Wilson and Ruff 1999). Thus, through these two different processes, source-sink and nomadic transient species maintain presence in the regional metacommunity and comprise a dynamic component of the local community.

The core-transient framework, integrated with an eco-evolutionary viewpoint, suggests that 
core and transient species may be responsible for maintaining different aspects of ecosystem function at a local site. Because of their higher local adaptation and stronger ability to exploit resources under local conditions, core species may be particularly important for maintaining ecosystem function (Grime 1998, Henderson and Magurran 2014). In contrast, because of their higher movement rates, transient species may be particularly important for maintaining local diversity through time and in response to disturbance (Dornelas et al. 2014, Henderson and Magurran 2014, Supp and Ernest 2014). Our site exhibits high annual composition turnover while generally maintaining species richness (Brown et al. 2001, Goheen et al. 2005), which indicates a role for nomadic transients in the regional metacommunity that can opportunistically fill empty niches and thus maintain community-level species richness. Our results suggest that species with locally adapted traits well suited to maximizing ecosystem functions related to resource use may also have lower movement rates. If so, this relationship between traits and movement patterns may be particularly important to explore in a metacommunity context.

The core-transient and core-satellite frameworks are merely two different ways of considering commonness and rarity in ecological systems. Temporal patterns of species persistence at a site depend on environmental filtering and competitive processes (Magurran and Henderson 2003, Coyle et al. 2013), but also partially depend on spatial patterns of habitat heterogeneity and movement between linked populations (Hanski 1982, Grime 1998, Gibson et al. 1999). A difficulty in linking the two ideas is that they define commonness and rarity in two different waysspecies are categorized by occupancy of a regionally defined area (core-satellite) or species are categorized by occupancy of a single site through time (core-transient). Combining the two frameworks would require modeling patch occupancy in the region through time, while allowing for core-satellite switching (e.g., Gaston and Lawton 1989, Gotelli 1991), and assigning core-transient species for each site across the time-series. Presumably, such a model would lead to several new categories of species: (1) regionally core species that remain core through- out the time-series and are temporally core at sites in which they occur, (2) regionally core species that switch to satellite species in poor years (e.g., experience local population crashes) or that display enhanced occupancy in good years (e.g., experience density dependent dispersal), and are mixed across sites as temporally core or transient, (3) satellite species that are temporally core in sites in which they occur, (4) satellite species that switch to regionally core in high resource years (e.g., irruptive dynamics), and are mixed across sites as temporally core or transient, (5) satellite species that switch the sites they occupy through time, and thus are temporally transient across the sites in which they occur (e.g., nomadism). Synthetically understanding the characteristics of species that display different or overlapping syndromes of commonness (e.g., locally abundant, high regional occupancy, and/or high temporal persistence) or rarity (locally rare, low regional occupancy, and/or low temporal persistence) remains a critical area for future research in community ecology.

Assessing whether there are life history implications for species using local versus regional scale processes for population maintenance is challenging. Long-term mark-recapture data that provides information on movement, survival, and reproduction rates across an entire community, including rare species, is very difficult data to obtain. Despite the shortcomings of our data, our results suggest that core and transient species may differ not only in their temporal persistence, but also in their use of landscapes, traits for resource use, and structure of their life histories. If other studies support our findings, it suggests that core-transient species traits should be modeled separately to understand how these groups might respond differently to environmental change. Core and source-sink transient species generally associated with low levels of gene flow or that are unable to track shifts in the location of suitable habitat across the landscape, would be predicted to undergo catastrophic decline under environmental changes that alter local conditions long-term (e.g., temperature, resource availability). Alternately, nomadic transient species that emigrate readily and exhibit high levels of gene flow among populations would be predicted to exhibit relatively small change in response to the same scenario. In the drive to better understand 
the response of biodiversity to perturbations, a temporal perspective of species demographics and persistence represents a critical link in identifying the linkages between local and regional richness patterns and predicting community response to change.

\section{ACKNOWLEDGMENTS}

We would like to thank P. Adler, M. Pfrender, E. P. White, L. Aubry, K. Shoemaker, B. Ross, M. Pendergast, S. Mortara, A. Hurlbert, J. Coyle, M. A. Leibold, The Weecology Lab at Utah State University (USU), and the Graham Lab at Stony Brook University for their valuable comments and discussion on the development of the ideas and analyses presented in the manuscript. One anonymous reviewer and Dr. Ilkka Hanski provided comments on the manuscript during the review process. We are grateful for the many scientists and volunteers that helped collect data for the long-term Portal Project. S. R. Supp was supported by NSF grant DEB-1100664 and DBI1400911, and fellowships from the USU Ecology Center and the USU School of Graduate Studies.

\section{Literature Cited}

Baguette, M., S. Blanchet, D. Legrand, V. M. Stevens, and C. Turlure. 2013. Individual dispersal, landscape connectivity and ecological networks. Biological Reviews 88:310-326.

Baker, R. R. 1978. The evolutionary ecology of animal migration. Hodder and Stoughton, London, UK.

Belmaker, J. 2009. Species richness of resident and transient coral-dwelling fish responds differently to regional diversity. Global Ecology and Biogeography 18:426-436.

Bininda-Emonds, O. R. P., M. Cardillo, K. E. Jones, R. D. E. MacPHee, R. M. D. Beck, R. Grenyer, S. A. Price, R. A. Vos, J. L. Gittleman, and A. Purvis. 2007. The delayed rise of present-day mammals. Nature 446:507-512.

Brown, J. H. 1998. The granivory experiments at portal. In W. J. Resetarits and J. Bernardo, editors. Experimental ecology: issue and perspectives. Oxford University Press, New York, New York, USA.

Brown, J. H., S. K. M. Ernest, J. M. Parody, and J. P. Haskell. 2001. Regulation of diversity: maintenance of species richness in changing environments. Oecologia 126:321-332.

Brown, J. H., and E. J. Heske. 1990. Control of a desertgrassland transition by a keystone rodent guild. Science 250:1705-1707.

Brown, J. H., and J. C. Munger. 1985. Experimental manipulation of a desert rodent community: food addition and species removal. Ecology 66:15451563.

Charlesworth, B. 1980. Evolution in age-structured populations. Cambridge University Press, Cambridge, UK.

Clutton-Brock, T. H. 1991. The evolution of parental care. Princeton University Press, Princeton, New Jersey, USA.

Connolly, S. E., et al. 2014. Commonness and rarity in the marine biosphere. Proceedings of the National Academy of Sciences USA 111:8524-8529.

Costello, M. J. and A. A. Myers. 1996. Turnover of transient species as contributor to the richness of a stable amphipod (Crustaceae) fauna in a sea inlet. Journal of Experimental Marine Biology and Ecology 202:49-62.

Coyle, J. R., A. H. Hurlbert, and E. P. White. 2013. Opposing mechanisms drive richness patterns of core and transient bird species. American Naturalist. 181:E83-90.

Diamond, J. M. 1974. Colonization of exploded volcanic islands by birds: the supertramp strategy. Science 184:803-806.

Dolan, J. R., M. E. Ritche, A. Tunin-Ley, and M. D. Pizay. 2009. Dynamics of core and transient species in the marine plankton: tintinnid ciliates in the north-west Mediterranean Sea. Journal of Biogeography 36:887-895.

Dornelas, M., N. J. Gotelli, B. McGill, S. Hideyasu, F. Moyes, C. Sievers, and A. E. Magurran. 2014. Assemblage time series reveal biodiversity change but not systematic loss. Science 344 296-299.

Ernest, S. K. M., and J. H. Brown. 2001. Delayed compensation for missing keystone species by colonization. Science 292:101-104.

Ernest, S. K. M., T. J. Valone, and J. H. Brown. 2009. Long-term monitoring and experimental manipulation of a Chihuahuan Desert ecosystem near Portal, Arizona, USA. Ecology 90:1708.

Felsenstein, J. 1985. Phylogenies and the comparative method. American Naturalist 125:1-15.

Gaggiotti, O. E. 1996. Population genetic models of source-sink metapopulations. Theoretical Population Biology 50:178-208.

Gaston, K. J., and J. H. Lawton. 1989. Insect herbivores on bracken do not support the core-satellite hypothesis. American Naturalist 134:761-777.

Ghalambor, C. K., and T. E. Martin. 2000. Parental investment strategies in two species of nuthatch vary with state-specific predation risk and reproductive effort. Animal Behavior 60:263-267.

Gibson, D. J., J. S. Ely, and S. L. Collins. 1999. The coresatellite species hypothesis provides a theoretical basis for Grime's classification of dominant, subordinate, and transient species. Journal of Ecology 87:1064-1067.

Goheen, J. R., E. P. White, S. K. M. Ernest, and J. H. 
Brown. 2005. Intra-guild compensation regulates species richness in desert rodents. Ecology 86:567573.

Gotelli, N. J. 1991. Metapopulation models: the rescue effect, the propagule rain, and the core-satellite hypothesis. American Naturalist 138:768-776.

Grime, J. P. 1998. Benefits of plant diversity to ecosystems: immediate, filter, and founder effects. Journal of Ecology 86:902-910.

Hanski, I. 1982. Dynamics of regional distribution: the core and satellite species hypothesis. Oikos 38:210 221.

Harmon, L. J., J. T. Weir, C. D. Brock, R. E. Glor, and W. Challenger. 2008. GEIGER: investigating evolutionary radiations. Bioinformatics 24:129-131.

Henderson, P. A., and A. E. Magurran. 2014. Direct evidence that density-dependent regulation underpins the temporal stability of abundant species in a diverse animal community. Proceedings of the Royal Society B 281:20141336.

Heske, E. J., J. H. Brown, and S. Mistry. 1994. Longterm experimental study of a Chihuahuan desert rodent community: 13 years of competition. Ecology 75:438-445.

Hoffmeister, D. F. 1986. Mammals of Arizona. University of Arizona Press and Arizona Game and Fish Department, Tucson, Arizona, USA.

Holt, R. D., and M. S. Gaines. 1992. Analysis of adaptation in heterogeneous landscapes: implications for the evolution of fundamental niches. Evolutionary Ecology 6:433-47.

Jonzen, N., E. Knudsen, R. D. Holt, and B. E. Saether. 2011. Uncertainty and predictability: the niches of migrants and nomads. Pages 91-109 in Animal migration: a synthesis. Oxford University Press, New York, NY, USA.

Kawecki, T. J. 2008. Adaptation to marginal habitats. Annual Review of Ecology, Evolution, and Systematics 39:321-342.

Kawecki, T. J., and R. D. Holt. 2002. Evolutionary consequences of asymmetric dispersal rates. American Naturalist 160:333-347.

Kembel, S. W., P. D. Cowan, M. R. Helmus, W. K. Cornwell, H. Morlon, D. D. Ackerly, S. P. Blomberg, and C. O. Webb. 2010. Picante: R tools for integrating phylogenies and ecology. Bioinformatics 26:1463-1464.

Kisdi, E. 2002. Dispersal: risk spreading versus local adaptation. American Naturalist. 159:579-596.

Kneitel, J. M., and J. M. Chase. 2004. Trade-offs in community ecology: linking spatial scales and species coexistence. Ecology Letters 7:69-80.

Laake, J. L. 2013. RMark: an R interface for analysis of capture-recapture data with MARK. AFSC Processed Report 2013-01. Alaska Fisheries Science Center, NOAA, National Marine Fisheries Service, Seattle Washington, USA.

ECOSPHERE www.esajournals.org
Laake, J. E., and E. Rexstad. 2008. RMark: an alternative approach to building linear models in MARK. Pages C1-C115 in E. Cooch and G. White, editors. Program MARK: a gentle introduction.

Lenormand, T. 2002. Gene flow and the limits to natural selection. Trends in Ecology and Evolution 17:183-89.

Loeuille, N., and M. A. Leibold. 2008. Evolution in metacommunities: on the relative importance of species sorting and monopolization in structuring communities. American Naturalist 171 788-799.

Mace, G. M., and P. H. Harvey. 1983. Energetic constraints on home-range size. American Naturalist 121:120-132.

Magurran, A. E., and P. A. Henderson. 2003. Explaining the excess of rare species in natural species abundance distributions. Nature 422:714-716.

McCauley, S. J. 2007. The role of local and regional processes in structuring dragonfly distributions across habitat gradients. Oikos 116:121-133.

McPeek, M. A., and R. D. Holt. 1992. The evolution of dispersal in spatially and temporally varying environments. American Naturalist 140:1010-1027.

Milstead, W. B., P. L. Meserve, A. Campanella, M. A. Previtali, D. A. Kelt, and J. R. Gutierrez. 2007. Spatial ecology of small mammals in north-central Chile: role of precipiation and refuges. Journal of Mammalogy 88:1532-1538.

Mueller, T., and W. F. Fagan. 2008. Search and navigation in dynamic environments: from individual behaviors to population distributions. Oikos 117:654-664.

Murray, B. G. 1967. Dispersal in vertebrates. Ecology 48:975-978.

O'Donnell, C. F. J. 2001. Home range and use of space by Chalinolobus tuberculatus, a temperate rainforest bat from New Zealand. Journal of Zoology 253:253-264.

O'Meara, B. C., L. Harmon, and J. Eastman. 2013. PhyloOrchard: important and/or useful phylogenetic datasets. $\mathrm{R}$ package version 0.3. https:// r-forge.r-project.org/R/?group_id=1217

Paulson, D. D. 1988. Chaetodipus hispidus. Mammalian Species, No. 320. The American Society of Mammalogists. http://dx.doi.org/10.2307/3504075

Paradis, E., J. Claude, and K. Strimmer. 2004. APE: analyses of phylogenetics and evolution in $\mathrm{R}$ language. Bioinformatics 20:289-290.

R Core Development Team. 2013. R: A language and environment for statistical computing. R Foundation for Statistical Computing. Vienna, Austria.

Reichmann, O. J., and M. V. Price. 1993. Ecological aspects of Heteromyid foraging. Pages 539-574 in H. H. Genoway and J. H. Brown, editors. Biology of the Heteromyidae. Special Publication, American Society of Mammalogists. http://dx.doi.org/10. 5962/bhl.title.39570 
Ricklefs, R. E., and M. Wikelski. 2002. The physiology/ life-history nexus. Trends in Ecology and Evolution 17:462-468.

Roshier, D., and J. Reid. 2003. On animal distributions in dynamic landscapes. Ecography 26:539-544.

Rousset, F., and S. Gandon. 2002. Evolution of the distribution of dispersal distance under distancedependent cost of dispersal. Journal of Evolutionary Biology 15:515-523.

Sibly, R. M., and J. H. Brown. 2007. Effects of body size and lifestyle on evolution of mammal life histories. Proceedings of the National Academy of Sciences 104:17707-17712.

Singleton, G. R., Sudarmaji, and S. Suriapermana. 1998. An experimental field study to evaluate a trap-barrier system and fumigation for controlling the rice field rat, Rattus argentiventer, in rice crops in West Java. Crop Protection 17:55-64.

Sokal, R. R., and F. J. Rohlf. 2012. Biometry. W. H. Freeman and Company, New York, New York, USA.

Stearns, S. 1992. The evolution of life histories. Oxford University Press, Oxford, UK.

Supp, S. R., and S. K. M. Ernest. 2014. Species-level and community-level responses to disturbance: a crosscommunity analysis. Ecology 95:1717-1723.

Thibault, K. M., E. P. White, and S. K. M. Ernest. 2004. Temporal dynamics in the structure and composition of a desert rodent community. Ecology 85:2649-2655.

Ulrich, W., and M. Ollik. 2004. Frequent and occasional species and the shape of relative-abundance distributions. Diversity and Distributions 10:263-269.

Urban, M. C., and D. K. Skelly. 2006. Evolving metacommunities: toward an evolutionary perspective on metacommunites. Ecology 87:16161626.

Urban, M. C., et al. 2008. The evolutionary ecology of metacommunities. Trends in Ecology and Evolu- tion 23:311-317.

Valone, T. J., M. Meyer, J. H. Brown, and R. M. Chew. 2002. Timescale of perennial grass recovery in desert arid grasslands following livestock removal. Conservation Biology 16:995-1002.

Valone, T. J., and M. R. Schutzenhofer. 2007. Reduced rodent biodiversity destabilizes plant populations. Ecology 88:26-31.

Vergnon, R., N. K. Dulvy, and R. P. Freckleton. 2009. Niches versus neutrality: uncovering the drivers of diversity in a species-rich community. Ecology Letters 12:1079-1090.

Waser, P. M. 1985. Does competition drive dispersal? Ecology 66:1170-1175.

Webster, W. D., and J. K. Jones, Jr. 1982. Reithrodontomys megalotis. Mammalian species. No. 167. American Society of Mammalogists. http://dx.doi. org/10.2307/3504020

Wiens, J. 2001. The landscape context of dispersal. In J. Clobert, editor. Dispersal. Oxford University Press, Oxford, UK.

Williams, D. F., H. H. Genoways, and J. K. Braun. 1993. Taxonomy and systematics. Pages 38-196 in H. H. Genoways and J. H. Brown, editors. Biology of the Heteromyidae. Special Publication, American Society of Mammalogists. http://dx.doi.org/10.5962/bhl. title.39570

White, G. C., and K. P. Burnham. 1999. Program MARK: survival estimation from populations of marked animals. Bird Study 46 Supplement:120138.

White, G. C., and E. Cooch. 2012. Program MARK: a gentle introduction. http://www.phidot.org/ software/mark/docs/book/

Wilson, D. E., and S. Ruff. 1999. The Smithsonian book of North American mammals. Smithsonian Institution Press in association with the American Society of Mammalogists, Washington, D.C., USA.

\section{SUPPLEMENTAL MATERIAL}

\section{Ecological Archives}

The Appendix and the Supplement are available online: http://dx.doi.org/10.1890/ES15-00239.1.sm 